\title{
Index System Study for the Operational Level Evaluation of Emergency Logistics
}

\author{
Dingzheng Huang ${ }^{1,}$ a, Zengzhu Qiu ${ }^{2, b}$ and Lei Zhang ${ }^{1, c}$ \\ ${ }^{1}$ National Defense University Joint Logistics College, Beijing, China; \\ ${ }^{2}$ Beijing Jiaotong University, Beijing, China. \\ a hngdngzhng@yeah.net, b13501201762@139.com, c zhanglei@lsec.cc.ac.cn
}

\begin{abstract}
Keywords: Emergency logistics, Operation level, Evaluation index system, Comprehensive evaluation method.
\end{abstract}

\begin{abstract}
The unconventionality and uncertainty of emergency logistics have higher and higher requirements for its operation. Using scientific evaluation index system to evaluate emergency logistics activities, summarize operational experience and master operational rules can not only provide data support for the optimization and adjustment of the existing emergency logistics resources allocation, but also provide reference for further emergency logistics operations to the direction of efficiency and low-cost. However, the existing emergency evaluation index system mainly aims at few isolated branches or a single one, lacking systematic coordination between various researches, particularly the post-disaster research results. In terms of evaluation methods, the descriptive and macroscopic research is vast while quantitative and operable research is rare. Therefore, this paper, starting from each branch of emergency logistics operations, coordinates operation procedures, emergency technology, equipment, material flow, information management, etc., using AHP method to establish a comprehensive evaluation index system to fully identify the current level and issues of emergency logistics operation. This research could provide quantitative basics for emergency logistics construction and management, and has certain practical significance and guidance for post-disaster reconstruction.
\end{abstract}

\section{Introduction}

Emergency logistics refers to a kind of special logistics activities that urgently guarantee the demand for materials, personnel and funds in response to emergencies such as serious natural disasters, public health emergencies, public security incidents and military conflicts, and enhances social stability Degree and reduce the losses caused by sudden disasters is of great significance. Therefore, studying the influencing factors of the emergency logistics support ability and constructing the evaluation system of China's emergency logistics support capability can provide a theoretical basis for improving the emergency logistics support capability, which will help to further improve the emergency logistics support measures, give play to the guarantee function of China's emergency logistics and weaken The negative impact of disasters plays an important role in promoting national security, promoting social development and ensuring the quality of people's life.

\section{Research Overview}

At present, emergency logistics has aroused the attention of many scholars, and all of them start from the subject they are engaged in. They have conducted a great deal of research and achieved fruitful results. For example, Zhao Jinxian et al constructed the multi-level evaluation index system for subway emergency response plan by analyzing the connotation of the emergency plan for subway and combining the principles and characteristics of the construction of the subway emergency plan index system[1]; Zheng wanbo and wu yanqing proposed the construction of a coal mine emergency rescue command information organization and material equipment research and decision-making system necessity and the system's ideas and methods[2]; Wang Xin and Zhang Yongling constructed 
the performance evaluation index system of emergency management from the perspective of moderate emergency response[3]; In view of the inherent characteristics of emergency process; Chi Nana selected 21 evaluation indexes and constructed a hierarchy of influencing factors of emergency response capability[4]; Wang Xiaodong, Wu Qunhong determined the public health emergency response evaluation index system after two rounds of expert consultation[5]; Ding Pengyu in research on emergency logistics support capability evaluation index system both at home and abroad, on the basis of using the interview method and statistical method to extract the emergency logistics capability factors literature initial indicators, and created our country emergency logistics support capability evaluation index system of evaluation scale, through exploratory factor analysis of the questionnaire survey data, build up our country emergency logistics support capability evaluation system[6]; Lin Haitao, RuYiGong andLi Hanqing, for coordination of emergency logistics system evaluation problems of weak links and related research, using the combination of qualitative and quantitative method, coordination of emergency logistics system evaluation in-depth exploration and research[7].

To sum up, at present, the researches on emergency logistics activities mainly focus on a single level. However, emergency activities involve all aspects and can not only focus on single accidents such as subway, coal mine or public health incidents, but also because of the characteristics of emergency logistics activities and social The complexity of the operation, the difficulty of calculating the operation level and the operation effect, and the many kinds of operations involved in the emergency activities and the wide range of fields. Each index has different importance to the target of the logistics activities, so the achievement degree of each index has different effect on the evaluation of the benefits of the emergency logistics activities. Therefore, it is necessary to conduct a systematic and scientific evaluation of the emergency response capability of major accidents and provide a quantitative basis for improving our country's ability to cope with major accidents. It is necessary to establish a comprehensive emergency outlook and establish a comprehensive operational plan that includes operational procedures, emergency technologies, facilities and equipment, materials flow, Information management, organizational structure, and human security mechanism subsystems. The basic and macro-strategic researches on emergency response activities are carried out.

\section{System Construction}

\subsection{Evaluation Method}

Because of the many factors involved in emergency logistics activities, we must establish a set of index system that can reflect the nature of the evaluation object as a whole and synthesize each index into a comprehensive index that can systematically measure the status of emergency logistics activities. In this way, evaluation method as a city safety evaluation is taken for granted. The comprehensive evaluation method has multi-index and multi-level characteristics. It consists of general comprehensive evaluation method, fuzzy comprehensive evaluation method, gray comprehensive evaluation method, multivariate statistical method, analytic hierarchy process and neural network evaluation method. Due to the serious lack of relevant data on emergency logistics activities, the accuracy and operability of disaster risk assessment in typical cities are severely limited. Therefore, in these comprehensive evaluation methods, the fuzzy comprehensive evaluation method, the gray comprehensive evaluation method, the neural network method and the AHP have more advantages.

\subsection{Index Screening}

Emergency logistics system is a complex large system involving different levels and systems of government, industry organizations and logistics enterprises, as well as different functions such as purchasing, warehousing, transportation and distribution, as well as information, laws and regulations, personnel, Theory and other different elements. Emergency logistics operation level evaluation index system is the basis of emergency response evaluation. Whether the selected index is comprehensive and objective or whether the index standard is accurate or not is relevant to the practicability and 
correctness of the whole evaluation result. Systematic principle, scientific principle, the particularity and universality of evaluation index, and the quantifiable principle of evaluation index are the principles that any index system should follow.

In recent years, the research on emergency logistics has been no longer confined to the preparation or distribution of such narrowly defined content but extends to all fields and places including operational processes, emergency technologies, facilities and equipment, material flow, information management and organizational structure All questions. These components are mutually reinforcing and closely linked. They are both independent and organic, and are the basic elements of the emergency logistics system. They are also the focus and focus of the emergency logistics system.

The logistics operation process. The logistics operation process is a whole series of orderly logistics activities carried out by the logistics system to achieve specific logistics objectives. It directly reflects material flow, equipment operation and resource consumption during the operation of the logistics system. Mainly include material financing, the military Federal Reserve, delivery and packaging, transport operations, temporary storage, terminal distribution, recycling operations.

Emergency technology. Emergency technology is based on emergency practical experience and the natural sciences and social science principles into a variety of process operation methods and skills and equipment and equipment. Demand forecasting technology, financing technology, reserve technology, secondary packaging and labeling technology, efficient handling technology, emergency transport technology, rapid delivery terminal dispensing technology

Facilities and equipment. Emergency Logistics Facilities Equipment systems refer to all kinds of fixed facilities such as platforms, terminals, traffic routes and routes with emergency logistics functions, as well as related equipment, tools and tools for transportation, storage, handling, packaging and processing, and other emergency logistics activities The necessary conditions and material basis for effective operation.

Materials System. Emergency supplies is an important basis for emergency logistics, is to achieve the basic conditions of material flow. The system of emergency supplies mainly includes the quantity and size of emergency supplies, the structure of varieties, the layout, the production capacity, the existing status and other related elements. Emergency supplies are an important material basis and basic safeguards for handling public emergencies. Emergency material system is the object of the role of emergency logistics system, is to achieve a "thing" can flow prerequisites.

Information Management. Emergency Logistics Information Management System Refers to the information network system used for the perception, transmission, analysis, aggregation and feedback of emergency logistics needs. It is equivalent to the "nervous system" of emergency logistics system and is a basic project in the construction of emergency logistics support layer. . Its components are composed of four aspects: the dependence of emergency rescue on information system, information tracking and real-time feedback, decision-making informatization level and management information application coverage.

Organizational Structure. Emergency logistics system refers to the emergency logistics system required for the operation of institutional settings (organizational structure), departmental responsibilities, and staffing, work processes. It is the "brain" of the emergency logistics system, which plays the role of command and dispatch logistics. It determines the operation flow, operation mode and operational efficiency of emergency logistics and is the core of the emergency logistics system. In order to be in the shortest possible time, in the most concise process, the quickest way to deliver emergency supplies to the scene of the disaster in order to reduce the extent of its negative impact and destruction, there must be efficient emergency logistics command system. The command and coordination system of emergency logistics is an important part of emergency command and coordination system and is the key and guarantee for effective and reasonable response to various emergencies.

Human Resources. Emergency logistics professionals include emergency logistics command and decision-making, scientific research, professional skills, operational use of professionals at all levels. It is the dynamic force of the emergency logistics system, concrete implementation of various tasks, 
directly determine the emergency logistics system and the quality and efficiency of emergency logistics support.

Policies and regulations. Emergency Logistics Policy and Regulation System refers to national laws, local (departmental and industrial) regulations and supporting rules and regulations system for emergency logistics, policy plans and emergency logistics plans prepared by the government, various technical standards and performance specifications, and mainly deals with emergency Logistics activities play a regulatory, incentives, constraints and so on.

Taken together, taking into account the emergency logistics operation level evaluation index system should take into account the type and extent of disaster, the affected area and the affected population. Each level of indicators can be set several secondary indicators. Evaluation of emergency logistics operations not only for operating processes, but also involves technology, facilities and equipment, information management summary. Emergency logistics activities is a systematic project, its evaluation should not only consider the results, but also consider the composition and process, but can be assessed from the operational level needs to coordinate the formulation of other indicators. According to this principle established emergency logistics operation level evaluation index system in Table 1.

Table 1. Emergency logistics operation level evaluation index system

\begin{tabular}{|c|c|c|c|}
\hline Target level & Factor layer & A level indicator level & Level two indicators \\
\hline \multirow{45}{*}{$\begin{array}{l}\text { Emergency Logistics Operation } \\
\text { Level Evaluation Index System }\end{array}$} & \multirow{7}{*}{$\begin{array}{l}\text { The logistics operation } \\
\text { process }\end{array}$} & Material financing & \\
\hline & & Military Federal Reserve & \\
\hline & & Delivery package & \\
\hline & & Transport operations & \\
\hline & & Temporary storage & \\
\hline & & End distribution & \\
\hline & & Recycling homework & \\
\hline & \multirow{7}{*}{ Emergency technology } & Demand forecasting technology & \\
\hline & & Raise technology & \\
\hline & & Reserve technology & \\
\hline & & $\begin{array}{l}\text { Secondary packaging and labeling } \\
\text { technology }\end{array}$ & \\
\hline & & $\begin{array}{l}\text { Efficient loading and unloading } \\
\text { handling technology }\end{array}$ & \\
\hline & & Emergency transport technology & \\
\hline & & $\begin{array}{c}\text { End point of rapid precision delivery } \\
\text { technology }\end{array}$ & \\
\hline & \multirow{4}{*}{ Facilities and equipment } & Storage & \\
\hline & & transport & \\
\hline & & Handling & \\
\hline & & Information platform construction & \\
\hline & \multirow{4}{*}{ Material system } & \multirow{2}{*}{ Supply response } & Fast production capacity \\
\hline & & & Material reserve capacity \\
\hline & & \multirow{2}{*}{ Transport capacity } & Delivery quality \\
\hline & & & Transport capacity \\
\hline & \multirow{3}{*}{ Information management } & Information tracking and feedback & \\
\hline & & Decision-making information level & \\
\hline & & Management information application & \\
\hline & \multirow{7}{*}{ Organizational structure } & \multirow[t]{2}{*}{ Construction level } & $\begin{array}{c}\text { The number of effective operation of the } \\
\text { team }\end{array}$ \\
\hline & & & Organizational structure is reasonable \\
\hline & & \multirow{3}{*}{ Coordination } & Tissue reaction time \\
\hline & & & Information transmission accuracy \\
\hline & & & Organizational ability to work together \\
\hline & & \multirow[b]{2}{*}{ Decision structure } & The ratio of policy makers \\
\hline & & & $\begin{array}{c}\text { Improve the degree of supporting } \\
\text { decision-making system }\end{array}$ \\
\hline & \multirow{9}{*}{ Human resources } & \multirow{3}{*}{ Rescue team } & The number of rescue teams \\
\hline & & & Rescue team quality \\
\hline & & & Rescue team can respond quickly \\
\hline & & \multirow{2}{*}{ Expert support staff } & Number of experts \\
\hline & & & Auxiliary support capabilities \\
\hline & & \multirow{2}{*}{ First-line implementation staff } & Number of frontline staff \\
\hline & & & First-line staff proficiency \\
\hline & & \multirow{2}{*}{ Policy makers } & Number of policy makers \\
\hline & & & Decision-makers personal qualities \\
\hline & \multirow{4}{*}{ Policies and regulations } & \multirow{2}{*}{ Legal protection } & Number of relevant legislation \\
\hline & & & Effective execution \\
\hline & & \multirow{2}{*}{ Emergency plan } & The number of related plans \\
\hline & & & Start the plan time \\
\hline
\end{tabular}




\section{Conclusion}

By summarizing the existing problems in the implementation of the existing standard system of emergency logistics, this paper analyzes and compares the existing standard system of emergency logistics activities to find out the advantages and disadvantages of the evaluation index system of emergency logistics operation level and discusses the basic principles of setting standards. The conclusions drawn in this study have certain guiding significance for building and improving the evaluation index system for the level of emergency logistics operations and have a guiding role in raising the level of emergency and quality safety in China. The main conclusions of this paper are as follows:

1. Evaluation of the status of emergency activities, the accumulation of successful experiences and continual enhancement of emergency response capabilities are the basic tasks for improving the capability of integrated disaster prevention and mitigation. At present, the research on the standard system of emergency logistics activities is still in its infancy.

2. Scientific emergency activities should stand at a systematic point of view, so the design of the existing standard system for emergency logistics should take "system" as the starting point and make a comprehensive evaluation so that the evaluation results are close to reality.

3. The current emergency logistics activities related to a serious lack of data should be integrated evaluation method as a method of emergency logistics evaluation system to improve the evaluation of emergency logistics activities accuracy and operability

\section{Acknowledgments}

This work is supported by the National Key Research and Development Programmed (2016YFC0803201).

Corresponding to zhanglei@1sec.cc.ac.cn

\section{References}

[1]. Zhao Jinxian, Wang Miaomiao, LI Kun. Computing of emergency plan of metro based on GRA-TOPSIS. Price Engineering. Vol. 03(2018), p. 75-77.

[2]. Zheng Wanbo, WU Yanqing. Research on Comprehensive Integration of Emergency Command and Command in Coal Mine. Occupational Health and Emergency Response.Vol. 06 (2011),p. 523-527.

[3]. Wang Xin, Zhang Yongling. Emergency Management Performance Evaluation Index System. Reform and Opening.Vol. 23(2017), p.70-73.

[4]. Chi Nana. Urban disaster emergency response evaluation index system. (Master's degree,Capital University of Economics and Business, China 2004). P.1-66.

[5]. Wu Qunhong, Hao Yanhua, Kang Zheng, Liang Libo, Chen Haiping. Research on the evaluation index system of emergency capacity for public health emergencies. Chinese Journal of Health Economics. Vol. 06(2013), p.47-50.

[6]. Ding Pengyu.Research on the Evaluation System of Emergency Logistics Support Ability in China. Logistics Technology. Vol. 15(2015), p.140-142.

[7]. Lin Haitao, Ru Yihong,Li Hanqing, Coordination Evaluation of Emergency Logistics System. Proceedings of the American Academy of Science Press, Shanghai, China. 2012, p.1100-1104. 